\title{
Prevalence of patellofemoral pain and knee pain in the general population of Chinese young adults: a community-based questionnaire survey
}

Xingquan $\mathrm{Xu}^{1,2}$, Chen Yao ${ }^{1,2}$, Rui Wu ${ }^{1}$, Wenjin Yan ${ }^{1}$, Yao Yao ${ }^{1}$, Kai Song ${ }^{1,2}$, Qing Jiang ${ }^{1,2^{*}}$ and Dongquan Shi ${ }^{1,2^{*}}$

\begin{abstract}
Background: Previous studies that have described the prevalence of patellofemoral pain (PFP) have been limited to samples of military personnel or sporting populations, and convincing data in the general Chinese population are lacking. The present study defined the prevalence of PFP and knee pain in the general population of Chinese young adults and evaluated whether gender, age, or body mass index (BMI) were associated with PFP.

Methods: An anonymous online questionnaire survey was open to the general public in China. A self-report questionnaire was used to specifically identify PFP. The population aged 18-40 years was enrolled in the study and completed the questionnaire. The prevalence of PFP and knee pain in the overall sample and in subgroups stratified by sex, age, and BMI was estimated. Logistic regression analysis was conducted to determine if there was a significant association between PFP and sex, age, or BMI.

Results: A total of 1153 participants were enrolled in the study. The prevalence of PFP in the overall sample and among the male and female participants was $20.7,20.3$, and $21.2 \%$, respectively. The prevalence of the knee pain in the overall sample and among the male and female participants was 35.6, 38.2, and 33.7\%, respectively. The prevalence of PFP in the subgroups stratified by age and BMI did not differ significantly between the groups. Gender, age, and BMI did not have significant associations with the prevalence of PFP.

Conclusion: PFP is common in the general Chinese population. Clinicians should direct more attention toward the early diagnosis of and interventions for PFP.
\end{abstract}

Keywords: Prevalence, Patellofemoral pain, Knee pain, Association, Questionnaire survey

\section{Background}

Patellofemoral pain (PFP) is a common lower extremity disorder in adolescents and physically active adults [1]. PFP is one of the most frequent causes of anterior knee pain and mainly affects young women [2,3]. Patients with PFP often experience pain behind or around the patella, usually without any structural changes [4]. PFP leads to restrictions in activities of daily life; it may also

* Correspondence: qingj@nju.edu.cn; shidongquan1215@163.com ${ }^{1}$ Department of Sports Medicine and Adult Reconstructive Surgery, Drum Tower Hospital, School of Medicine, Nanjing University, 321 Zhongshan Road, Nanjing, Jiangsu 210008, People's Republic of China

Full list of author information is available at the end of the article be a risk factor of patellofemoral joint osteoarthritis (PFJOA) [5, 6].

Studying the epidemiology of PFP may be useful in preventing and controlling the disease. The prevalence of PFP is commonly reported as high, especially in young adolescents aged 12 to 17 years old [7]. A review study demonstrated that the prevalence of PFP may be up to $40 \%$ [8]. However, the majority of the studies regarding the prevalence of PFP were limited to samples of military personnel, sporting populations, or school children [8-11]. Thus far, few studies have examined data from general populations. Recently, the SNAPPS questionnaires have been developed to assess the prevalence of PFP within the general population. While they

(c) The Author(s). 2018 Open Access This article is distributed under the terms of the Creative Commons Attribution 4.0 International License (http://creativecommons.org/licenses/by/4.0/), which permits unrestricted use, distribution, and 
identified a prevalence rate of $22.7 \%$, the study only included 111 patients [12]. There is still a need to evaluate the prevalence in a large-scale population-based study.

To our knowledge, convincing data in general Chinese populations is not yet available. Thus, the present study assessed the prevalence of PFP in the general population of Chinese young adults (aged 18-40 years) using a selfreport questionnaire that was designed to identify individuals with PFP in the community.

\section{Methods}

\section{Study design}

This study was an anonymous online questionnaire survey of the general population of Chinese young adults. The Ethics Committee of Nanjing Drum Tower Hospital approved the survey. All subjects signed informed consents by marking a checkbox, and the information of the subjects was protected. A self-report questionnaire (SNAPPS-Survey Instrument for Natural History, Etiology, and Prevalence of Patellofemoral Pain Studies) [12] was transformed into an online format through a website (www.lediaocha.com). The questionnaire in this study was designed to be completed and spread through the social media platform WeChat, as almost everyone in China has WeChat on their mobile phone. Thus, people from various careers and different cities in China could be enrolled in this study.

\section{Participants}

The sample was comprised of adults aged 18 to 40 years old who completed and submitted the questionnaire on the web platform. The participants included were engaged in a variety of occupations. Participants who were outside the age range or unable to complete the questionnaire were excluded from the study.

\section{Measures}

The SNAPPS questionnaire used in this study was designed by Dey et al. in 2016 [12]. The questionnaire was designed to discriminate between the individuals in the community with and without PFP. The SNAPPS questionnaire was comprised of four sections. The first section identified individuals with knee pain based on one specific question. The second section addressed the clinical features of the knee problem. The third section encompassed difficulty or pain during specific activities that were commonly associated with a knee problem. The last section was designed to identify the location of the pain using a knee pain map. The designers conducted a comparative study including soft-tissue injury patients, PFP patients, and adults without knee problems [12]. The results showed that the measurement properties of the questionnaire were satisfactory based on the scoring, limited to sections 2 and 4, with a high sensitivity and specificity (both $>90 \%$ ) [12]. The threshold score was set to $\geq 6$ for PFP. Thus, our online SNAPPS questionnaire consisted of sections 1,2, and 4 from the original questionnaire. In the first section, the participants provided their demographic information (sex, age, height, body weight) and answered the question "Have you had pain or problems in the last year in or around the knee?" If the answer was "no," the questionnaire would be submitted, and the participants would be classified into the group of patients with no knee pain. If the answer was "yes," the subjects would complete the remaining two sections (Table 1). All of the data were collected, and the scores on sections 2 and 4 were calculated. There were seven questions in section 2 , and the participants could get " 0 " or " 1 " score for each question according to their answer. In section 2 , the minimum score was 0 and the maximum score was 7 (Table 1). In section 4, a picture of a knee joint was shown with the medial, lateral and inferior part of the patella labeled. In total, six areas were labeled in both knees. The participants were asked to determine the number of areas in which they experienced pain in both knees. One point was awarded for each pain area selected. In section 4 , the minimum score was 0 and the maximum score was 6 (Table 1). The final scores of the participants were shown by calculating the scores on sections 2 and 4 . The participants with a total score $<6$ were considered to have self-reported knee pain but not PFP. The participants with a total score $\geq 6$ were considered to have PFP.

\section{Statistical analysis}

Descriptive statistics were used to describe the characteristics of the participants. The prevalence of PFP and knee pain was calculated in the overall sample and in the male and female participants. The proportion of PFP participants in the knee pain population was also analyzed. The difference in the prevalence of PFP and knee pain among male and female groups was analyzed by a chi-square test. Logistic regression analysis was used to examine the association between each factor (gender, age, BMI) and the prevalence of PFP. Furthermore, the participants were categorized into small groups according to age $(<20,20-30$, and $31-40$ years $)$ as well as BMI $(<18.5,18.5-24$, and $>24)$. The above data were analyzed again in subgroups. $P \leq 0.05$ was considered statistically significant. All of the statistical analyses were performed using SPSS 19.0 (SPSS Inc., Chicago, IL, USA).

\section{Results}

A total of 1265 questionnaires were submitted. After excluding participants who were outside the age range or unable to complete the questionnaire, 1153 participants (676 females and 477 males) from different cities of China were enrolled in the present study. The mean age of the participants was $27.33 \pm 4.38$ years (Table 2). 
Table 1 Items and methods for scoring, according to SNAPPS

\begin{tabular}{|c|c|c|}
\hline Items & \multicolumn{2}{|l|}{ Scoring of sections } \\
\hline \multicolumn{3}{|l|}{ Patient characteristics } \\
\hline \multicolumn{3}{|l|}{ Sex } \\
\hline \multicolumn{3}{|l|}{ Age } \\
\hline \multicolumn{3}{|l|}{ Height } \\
\hline \multicolumn{3}{|l|}{ Body weight } \\
\hline \multirow[t]{2}{*}{ Section 1: } & \multicolumn{2}{|l|}{ Answer } \\
\hline & Yes & No \\
\hline Have you had pain or problems in the last year in or around the knee? & $\begin{array}{l}\text { Continue to finish sections } \\
2 \text { and } 4\end{array}$ & Submit \\
\hline \multirow[t]{2}{*}{ Section 2: Clinical features } & \multicolumn{2}{|l|}{ Answers and scores } \\
\hline & Yes & No \\
\hline Did you have pain or problems in one or both of your knees? & 1 & 0 \\
\hline Have you had surgery on your knee? & 0 & 1 \\
\hline Have you ever had a knee cap that has gone out of joint (dislocated)? & 0 & 1 \\
\hline Since the beginning of your knee problem, has your knee ever swelled up? & 0 & 1 \\
\hline Have you had pain and discomfort for more than one month? & 1 & 0 \\
\hline $\begin{array}{l}\text { Thinking about your right (left) knee, what do you consider your main problem with your knee? Did you } \\
\text { experience pain or discomfort? }\end{array}$ & 1 & 0 \\
\hline Thinking about your right (left) knee, did your current knee problem come on? & 1 & 0 \\
\hline In the presence of bilateral pain, a maximum score of 1 was given for each clinical feature & \multicolumn{2}{|c|}{$\begin{array}{l}\text { The minimum score was } 0 \text {, and the } \\
\text { maximum score was } 7 \text { in this } \\
\text { section }\end{array}$} \\
\hline Section 4: Knee pain map & \multicolumn{2}{|l|}{ Scores } \\
\hline \multirow{2}{*}{$\begin{array}{l}\text { The participants were asked to determine the number of areas in which they experience pain (total of six } \\
\text { areas in both knees) }\end{array}$} & \multicolumn{2}{|l|}{ One area gets a score of 1} \\
\hline & \multicolumn{2}{|c|}{$\begin{array}{l}\text { In this section, the minimum score } \\
\text { was } 0 \text {, and the maximum score was } \\
6\end{array}$} \\
\hline
\end{tabular}

The mean BMI was $21.79 \pm 2.92$ (Table 2). However, no significant difference was observed in age between the male and female participants $(27.39 \pm 3.97$ vs. $27.29 \pm 4.66$, $P=0.130$ ). The BMI of the male subjects was significantly higher than that of their female counterparts $(23.31 \pm 2.92$ vs. $20.72 \pm 2.39, P<0.001)$ (Table 2$)$.

Next, the prevalence of PFP in the overall sample (239 of $1153,20.7 \%$ ) and in the male (97 of $477,20.3 \%$ ) and female (142 of 676, 21.2\%) participants was calculated (Table 2). No significant difference was observed between the male and female groups $(P=0.711)$. Of all
1153 participants, 411 experienced knee pain, with a prevalence of knee pain of $35.6 \%$ (Table 2). More male participants experienced knee pain compared to their female counterparts (38.2 vs. 33.7\%), although no significant difference was detected $(P=0.111)$. Furthermore, the proportion of participants with PFP with respect to knee pain was analyzed. The proportion of knee pain participants with PFP was $58.3 \%$ (239 of 410 ) in the total sample, 53.3\% (97 of 182) among the male participants, and $62.3 \%$ (142 of 228 ) among the female participants (Table 2). Logistic regression analysis was conducted to

Table 2 Characteristics of the participants and the prevalence of PFP and knee pain

\begin{tabular}{lllll}
\hline & Total & Men & Women & $P$ value (Men vs Women) \\
\hline Number of subjects & 1153 & $477(41.4 \%)$ & $676(58.6 \%)$ & - \\
Age $($ mean \pm SD) & $27.33 \pm 4.38$ & $27.39 \pm 3.97$ & $27.29 \pm 4.66$ & 0.130 \\
BMI (mean \pm SD) & $21.79 \pm 2.92$ & $23.31 \pm 2.92$ & $20.72 \pm 2.39$ & $<0.001$ \\
PFP & $239(20.7 \%)$ & $97(20.3 \%)$ & $142(21.2 \%)$ & 0.711 \\
Knee pain & $410(35.6 \%)$ & $182(38.2 \%)$ & $228(33.7 \%)$ & 0.111 \\
PFP/knee pain & $239(58.3 \%)$ & $97(53.3 \%)$ & $142(62.3 \%)$ & 0.067 \\
\hline
\end{tabular}


detect whether gender, age, and BMI were associated with PFP. The results showed that gender, age, and BMI were not related to the prevalence of PFP in the overall sample (Table 3).

\section{Discussion}

PFP mainly affects the young population. The prevalence of PFP in the general population still needs further exploration [12, 13]. To the best of our knowledge, this is the first study in China focusing on the prevalence of PFP and knee pain in the general population. The present study provided data on the general population of Chinese young adults and analyzed whether gender, age, or BMI were related to the prevalence of PFP.

The results showed that the overall prevalence of PFP in young Chinese individuals was $20.7 \%$, whereas the prevalence in male and female subjects was 20.3 and $21.1 \%$, respectively (Table 2). The prevalence of PFP that was reported by previous studies varied $[2,8,12,14-16]$. Generally, the data indicated relatively lower prevalence in this study. Different personnel constitution of the sample structure and diagnostic methods may contribute to the differences in prevalence. The majority of previous studies were based on specific populations (e.g., military, students, and sporting personnel) that may perform higher levels of activity than the general population and may be of different ages compared to our study sample. On the other hand, unlike other studies, we used a self-report questionnaire to identify PFP, which may influence the results to some extent. The method we used may omit some cases or misclassify other knee pathologies as PFP.

In the present study, the prevalence of PFP in females was slightly higher than that in males (21.2 vs. $20.3 \%)$; however, no significant difference was detected. PFP is known to occur more frequently in females than in males [3, 17]. Several studies speculated that anatomical alignments and biomechanical factors might explain this phenomenon. Current prospective evidence showed that knee valgus displacement during landing could predict the risk of developing PFP [18]. Studies demonstrated that female athletes displayed increased knee abduction alignment compared to males during pivoting movement and drop landing $[19,20]$. The prevalence of PFP was not significantly different between genders in the present study. Again, we supposed that different personnelbased sample structures and diagnostic methods might lead to the present results. This study also showed that PFP populations constituted more than half of the knee pain participants, which is sufficient to capture the attention of professionals to diagnose and treat PFP in clinical work.

A logistic regression analysis was conducted to identify if gender, age, and BMI were associated with the prevalence of PFP; however, such an association was not established (Table 3). Although the etiology of PFP has been shown to be multifactorial [21, 22], a consensus regarding the factors contributing to PFP is still lacking [23]. Several studies have been conducted to assess the factors associated with the prevalence of PFP. Some variables, such as BMI, height, mass, age, gender, hip weakness, and somatotype, have been examined; however, no significant associations have been found [2, 13, 24-28]. Higher-quality studies are needed to further explore the factors associated with the prevalence of PFP.

One feature of the present study was to use the social media platform WeChat to recruit participants and gather information. WeChat is very popular in China. Almost every adult has WeChat on their mobile phone. Thus, we can spread the questionnaire to various populations from different cities of China. The original SNAPPS designed by Dey et al. [12] contained four sections. However, their study showed that the measurement properties of the questionnaire were improved by omitting section 3 [12]. Additionally, too many questions in the questionnaire may have reduced the completion rate of our study. Based on these considerations, we removed section 3 in our online questionnaire.

The present study has some limitations. One of the main limitations is the lack of a standard definition of PFP. Both the clinical examination and self-reported questionnaire have shortcomings. The questionnaire is relatively suitable for a large-scale online-based survey. The SNAPPS used in this study has not been evaluated for diagnostic accuracy within a community setting. As

Table 3 Logistic regression analysis to identify associated factors with the prevalence of PFP

\begin{tabular}{|c|c|c|c|c|c|c|}
\hline \multirow[t]{2}{*}{ Variable } & \multirow{2}{*}{$\begin{array}{l}\text { With PFP } \\
N=239\end{array}$} & \multirow{2}{*}{$\begin{array}{l}\text { Without PFP } \\
N=914\end{array}$} & \multicolumn{2}{|c|}{ Univariate logistic regression } & \multicolumn{2}{|c|}{ Multivariate logistic regression } \\
\hline & & & $\mathrm{OR}(95 \% \mathrm{Cl})$ & $P$ & $\mathrm{OR}(95 \% \mathrm{Cl})$ & $P$ \\
\hline $\mathrm{Age}^{\mathrm{a}}$ & $27.23 \pm 4.14$ & $27.36 \pm 4.45$ & $0.993(0.962-1.026)$ & 0.691 & $0.986(0.954-1.020)$ & 0.416 \\
\hline$B M I^{b}$ & $22.01 \pm 2.95$ & $21.73 \pm 2.91$ & $1.033(0.985-1.084)$ & 0.180 & $1.051(0.995-1.111)$ & 0.075 \\
\hline Gender $^{c}$ & $97(40.6 \%)$ & $380(41.6 \%)$ & $1.042(0.780-1.392)$ & 0.782 & $1.187(0.857-1.643)$ & 0.302 \\
\hline
\end{tabular}

Age: Mean \pm SD

BMI: Mean \pm SD

Gender: Male (percentage)

${ }^{a}$ OR for age is for an increase of 1 year

${ }^{b}$ OR for BMI is for a 1-unit increase

${ }^{c}$ OR for gender uses male as the reference group 
mentioned above, some of the questions in the questionnaire may omit some cases or lead to misclassification of other knee pathologies as PFP. We defined the age range as 18-40 years, which may influence the results to a certain degree. The prevalence in older or younger populations may differ from that in the defined age range. Some juveniles may be restricted in their use of mobile phones in China, and adults older than 40 years old may get knee osteoarthritis. For this reason, only 18- to 40-year-old participants were enrolled in this study. The number of participants enrolled in the study was relatively small, which is another main limitation.

\section{Conclusion}

The current community-based study is the first to evaluate the prevalence of PFP and knee pain in the general Chinese population. The study showed that the overall prevalence of PFP and knee pain in the sample was 20.7 and $35.6 \%$, respectively. Gender, age, and BMI did not seem to be associated with the prevalence of PFP in the general Chinese population. There is still a need for an in-depth study with a large number of participants in China examining the prevalence of PFP and associated factors.

\section{Abbreviations}

BMI: body mass index; PFJ: patellofemoral joint; PFP: prevalence of patellofemoral pain; SNAPPS: Survey instrument for Natural History, Etiology, and Prevalence of Patellofemoral Pain Studies

\section{Acknowledgments}

The authors would like to acknowledge the participants who participated in the study.

\section{Authors'contributions}

$X Q X, Q J$ and DQS were involved in conception and design of the study. CY, RW and WJY made contribution to acquisition of data. YY and KS were involved in analysis of the study. XQX wrote the manuscript. All authors read and approved the final manuscript.

\section{Funding}

This work was supported by the Projects of International Cooperation and Exchanges Natural Science Foundation of China (NSFC) (81420108021), National Key Technology Support Program (2015BAl08B02), Excellent Young Scholars NSFC (81622033), NSFC (81572129). Jiangsu Provincial Key Medical Center Foundation, Jiangsu Provincial Medical Talent Foundation and Jiangsu Provincial Medical Outstanding Talent Foundation, Social Development Project of Jiangsu Provincial Science and Technology Department (BE2016609).

\section{Availability of data and materials}

The datasets used and/or analysed during the current study are available from the corresponding author on reasonable request.

\section{Ethics approval and consent to participate}

The Ethics Committee of Nanjing Drum Tower Hospital approved the survey. All subjects signed informed consents by marking a checkbox. The study was conducted according to the Helsinki Declaration (Ethical Principles for Medical Research Involving Human Subjects).

\section{Competing interests}

The authors declare that they have no competing interests. QJ is a member of the editorial board of BMC Musculoskeletal Disorders.

\section{Publisher's Note}

Springer Nature remains neutral with regard to jurisdictional claims in published maps and institutional affiliations.

\section{Author details}

'Department of Sports Medicine and Adult Reconstructive Surgery, Drum Tower Hospital, School of Medicine, Nanjing University, 321 Zhongshan Road, Nanjing, Jiangsu 210008, People's Republic of China. ${ }^{2}$ Joint Research Center for Bone and Joint Disease, Model Animal Research Center (MARC), Nanjing University, Nanjing, Jiangsu 210093, People's Republic of China.

Received: 4 January 2018 Accepted: 8 May 2018

Published online: 24 May 2018

\section{References}

1. Wood L, Muller S, Peat G. The epidemiology of patellofemoral disorders in adulthood: a review of routine general practice morbidity recording. Prim Health Care Res Dev. 2011;12(2):157-64.

2. Boling M, Padua D, Marshall S, Guskiewicz K, Pyne S, Beutler A. Gender differences in the incidence and prevalence of patellofemoral pain syndrome. Scand J Med Sci Sports. 2010;20(5):725-30.

3. Robinson RL, Nee RJ. Analysis of hip strength in females seeking physical therapy treatment for unilateral patellofemoral pain syndrome. J Orthop Sports Phys Ther. 2007;37(5):232-8.

4. Al-Hakim W, Jaiswal PK, Khan W, Johnstone D. Suppl 2: the non-operative treatment of anterior knee pain. Open Orthop J. 2012;6:320.

5. Dye SF. The pathophysiology of patellofemoral pain: a tissue homeostasis perspective. Clin Orthop Relat Res. 2005;436:100-10.

6. Thomas MJ, Wood L, Selfe J, Peat G. Anterior knee pain in younger adults as a precursor to subsequent patellofemoral osteoarthritis: a systematic review. BMC Musculoskelet Disord. 2010;11(1):201.

7. Rathleff MS, Skuldbøl SK, Rasch MNB, Roos EM, Rasmussen S, Olesen JL. Care-seeking behaviour of adolescents with knee pain: a populationbased study among 504 adolescents. BMC Musculoskelet Disord. 2013;14(1):225

8. Callaghan MJ, Selfe J. Has the incidence or prevalence of patellofemoral pain in the general population in the United Kingdom been properly evaluated? Phys Ther Sport. 2007:8(1):37-43.

9. Mølgaard C, Rathleff MS, Simonsen O. Patellofemoral pain syndrome and its association with hip, ankle, and foot function in 16-to 18-year-old high school students: a single-blind case-control study. J Am Podiatr Med Assoc. 2011;101(3):215-22.

10. Rathleff MS, Roos EM, Olesen JL, Rasmussen S. Early intervention for adolescents with patellofemoral pain syndrome-a pragmatic cluster randomised controlled trial. BMC Musculoskelet Disord. 2012;13(1):9.

11. Smith BE, Selfe J, Thacker D, Hendrick P, Bateman M, Moffatt F, et al. Incidence and prevalence of patellofemoral pain: a systematic review and meta-analysis. PLoS One. 2018;13(1):e0190892.

12. Dey P, Callaghan M, Cook N, Sephton R, Sutton C, Hough E, et al. A questionnaire to identify patellofemoral pain in the community: an exploration of measurement properties. BMC Musculoskelet Disord. 2016;17(1):237.

13. Witvrouw E, Callaghan MJ, Stefanik JJ, Noehren B, Bazett-Jones DM, Willson $J D$, et al. Patellofemoral pain: consensus statement from the 3rd international patellofemoral pain research retreat held in Vancouver, September 2013. Br J Sports Med. 2014;48(6):411-4.

14. Boling MC, Padua DA, Marshall SW, Guskiewica K, Pyne S, Beutler A, et al. A prospective investigation of biomechanical risk factors for patellofemoral pain syndrome: the joint undertaking to monitor and prevent $A C L$ injury (JUMP-ACL) cohort. Am J Sports Med. 2009;37(11):2108-16.

15. Fairbank JC, Pynsent PB, van Poortvliet JA, Phillips H. Mechanical factors in the incidence of knee pain in adolescents and young adults. J Bone Joint Surg Br. 1984;66(5):685-93.

16. Foss KDB, Myer GD, Magnussen RA, Hewett TE. Diagnostic differences for anterior knee pain between sexes in adolescent basketball players. J Athl Enhanc. 2014;3(1):1814.

17. Fulkerson JP. Diagnosis and treatment of patients with patellofemoral pain. Am J Sports Med. 2002;30(3):447-56.

18. Holden S, Boreham C, Doherty C, Delahunt E. Two-dimensional knee valgus displacement as a predictor of patellofemoral pain in adolescent females. Scand J Med Sci Sports. 2017;27(2):188-94. 
19. Ford KR, Myer GD, Hewett TE. Valgus knee motion during landing in high school female and male basketball players. Med Sci Sports Exerc. 2003; 35(10):1745-50.

20. Ford KR, Myer GD, Toms HE, Hewett TE. Gender differences in the kinematics of unanticipated cutting in young athletes. Med Sci Sports Exerc. 2005;37(1):124-9.

21. Davis IS, Powers C. Patellofemoral pain syndrome: proximal, distal, and local factors. J Orthop Sports Phys Ther. 2010;40(3):A3-5.

22. Thomeé R, Augustsson J, Karlsson J. Patellofemoral pain syndrome. Sports Med. 1999;28:245-62.

23. Lankhorst NE, Bierma-Zeinstra SMA, van Middelkoop M. Factors associated with patellofemoral pain syndrome: a systematic review. Br J Sports Med. 2013;47(4):193-206.

24. Halabchi F, Mazaheri R, Seif-Barghi T. Patellofemoral pain syndrome and modifiable intrinsic risk factors; how to assess and address? Asian J Sports Med. 2013;4(2):85.

25. White LC, Dolphin P, Dixon J. Hamstring length in patellofemoral pain syndrome. Physiotherapy. 2009;95(1):24-8.

26. Whyte EF, Moran K, Shortt CP, Marshall B. The influence of reduced hamstring length on patellofemoral joint stress during squatting in healthy male adults. Gait Posture. 2010;31(1):47-51.

27. Hudson Z, Darthuy E. Iliotibial band tightness and patellofemoral pain syndrome: a case-control study. Man Ther. 2009;14(2):147-51.

28. Thijs Y, Pattyn E, Van Tiggelen DV, Rombaut L, Witvrouw E. Is hip muscle weakness a predisposing factor for patellofemoral pain in female novice runners? A prospective study. Am J Sports Med. 2011;39(9):1877-82.

Ready to submit your research? Choose BMC and benefit from:

- fast, convenient online submission

- thorough peer review by experienced researchers in your field

- rapid publication on acceptance

- support for research data, including large and complex data types

- gold Open Access which fosters wider collaboration and increased citations

- maximum visibility for your research: over $100 \mathrm{M}$ website views per year

At BMC, research is always in progress.

Learn more biomedcentral.com/submissions 